\title{
Prognostic role of platelet to Iymphocyte ratio in esophageal cancer: A meta-analysis
}

\author{
Qing-Tao Zhao ${ }^{1, *}$, Xiao-Peng Zhang ${ }^{1, *}$, Hua Zhang ${ }^{1, *}$ and Guo-Chen Duan ${ }^{1}$ \\ ${ }^{1}$ Department of Thoracic Surgery, Hebei General Hospital, Shijiazhuang 050051, Hebei, PR China \\ "These authors have contributed equally to this work \\ Correspondence to: Guo-Chen Duan, email: hbghospital@163.com \\ Keywords: platelet to lymphocyte ratio; esophageal cancer; prognosis; meta-analysis \\ Received: June 06, $2017 \quad$ Accepted: October 28, $2017 \quad$ Published: November 20, 2017
}

Copyright: Zhao et al. This is an open-access article distributed under the terms of the Creative Commons Attribution License 3.0 (CC BY 3.0), which permits unrestricted use, distribution, and reproduction in any medium, provided the original author and source are credited.

\section{ABSTRACT}

Purpose: The prognostic role of inflammation index like platelet to lymphocyte ratio (PLR) in esophageal cancer remains controversial. We evaluated the prognostic significance of PLR in esophageal cancer patients.

Methods: We searched databases to identify relevant literatures. Pooled hazard ratios (HRs) and $95 \%$ confidence intervals (CIs) were calculated. A meta-analysis was performed to evaluate the prognostic value of PLR in patients with esophageal cancer.

Results: A total of 6,699 patients from 16 studies (17 cohorts) were finally enrolled in the meta-analysis. The results demonstrate that the elevated PLR predicted poorer overall survival (OS) (HR: 1.389, 95\% CI: 1.161-1.663) and disease-free survival (DFS) (HR: 1.404, 95\% CI: 1.169-1.687) and cancer-specific survival (CSS) (HR: 1.686, 95\% CI: 1.146-2.480) in patients with esophageal cancer. Subgroup analysis revealed that the elevated PLR was also associated with poor OS in esophageal cancer treated by surgery (HR: 1.492, 95\%CI: $1.149-1.938, \mathrm{P}<0.05$ ) and mixed treatment (HR: 1.222, 95\%CI: 1.009-1.479, P<0.05). In addition, PLR Cutoff value $\leq 160$ (HR: 1.484, 95\%CI: 1.088-2.024, $P<0.05$ ) and PLR Cut-off value $>160$ (HR: 1.391, 95\%CI: 1.161-1.666, P<0.05).

Conclusion: This meta-analysis result suggested that PLR might be a significant predicative biomarker of poor prognosis for esophageal cancer patients.

\section{INTRODUCTION}

Esophageal cancer is one of the most common cancers in the worldwide [1]. Despite the research on the treatment of esophageal cancer and the use of increasingly advanced technology in its treatment, the overall survival (OS) and progression-free survival (PFS) are still poor due to the high rate of recurrence and rapid progression [2, 3]. Therefore, there is an urgent need for us to identify better prognostic biomarkers, especially serum predictive biomarkers, for prognosis in patients with esophageal cancer.

Recently, more and more evidence showed that a systemic inflammatory response could play an important role in the prognosis of various cancers [4-
7]. Various inflammatory factors, such as C-reactive protein (CRP), neutrophil to lymphocyte ratio(NLR), and platelet to lymphocyte ratio (PLR), have been investigated in various types of cancers $[8,9]$. PLR, calculated as platelet counts divided by lymphocyte counts, has been associated with worse survival for a variety of cancers including the lung cancer [10], colorectal cancer [11], gastric cancer [12] and so on. Recent studies demonstrated a potential prognostic role of PLR in esophageal cancer patients [13-16]. However, due to the inconsistent results, the current opinion on the prognostic role of PLR in esophageal cancer remains controversial $[13,14,16]$. We therefore conducted a meta-analysis to comprehensively and systematically understand the prognostic value of 
PLR in esophageal cancer. In this study, we aimed at assessing the prognostic significance of high PLR for survival in patients with esophageal cancer.

\section{RESULTS}

\section{Study characteristics}

Our database search retrieved a total of 112 articles. We eliminated 83 articles for various reasons based on the title and abstract, leaving 29 studies to scrutinize with a full text review. Of the 29 studies, three were reported by the same study center and the patients were overlapping or partly overlapping in the studies $[15,17,18]$. To avoid duplicate counting, only one study with more complete data was selected [15]. Therefore, 16 studies (17 cohorts) with a total of 6699 patients published between 2011 and 2017 were finally enrolled in our meta-analysis [13-16, 19-30]. The processes of study selection were summarized in the flow diagram (Figure 1). The detailed characteristics of all included studies are summarized in Table 1. All 17 were retrospective observational cohort studies. The 16 included studies evaluated a total of 6699 patients, including 6303 with squamous cell carcinoma, 353 with adenocarcinoma, 43 with small cell carcinoma. We evaluated studies from 4 different countries, including 10 studies from China, 2 from Japan, 2 from the United States and 2 from the United Kingdom.

HRs and 95\% CIs were reported directly in 16 studies, 11 of which calculated HRs by the multivariate analysis and 13 via univariable analysis. 9 of these cohorts had $\geq 300$ patients and 8 cohorts enrolled $<300$ patients. The cut-off values applied in the studies were not consistent ranging from 103 to 429.7. 6 cohorts used a PLR greater than 160 , while 8 cohorts had a PLR cutoff value of 160 or less. The characteristics of the included studies were shown in Table 1.

\section{PLR and OS in esophageal cancer}

11 cohorts presented the relationship between PLR and OS in esophageal cancer. Though with significant heterogeneity $\left(I^{2}=79.9 \%, P h<0.01\right)$, therefore, a randomeffects model was applied. Our results revealed that elevated PLR were significantly correlated with worse OS (HR: $1.389,95 \%$ CI: 1.161-1.663, $P<0.001$ ) (Figure $2)$. In a further investigation, subgroup analyses were performed (Table 2). 5 cohorts presented the information of PLR correlated with OS in esophageal cancer initially treated by surgery. we revealed the pooled HR was 1.492 (95\%CI: $1.149-1.938, P<0.05)$ for patients treated by surgery and $1.222(95 \% \mathrm{CI}: 1.009-1.479, P<0.05)$ for patients treated by mixed treatment. In addition, subgroup analysis was performed by the sample size $(\geq 300$ and $<300$ ), cut-off value (cut-off value $\leq 160$ and cut-off value>160) and (Univariate analysis and Multivariate analysis).

\section{PLR and DFS and CSS in esophageal cancer}

A fixed-effects model $(I=0 \%, P h=0.597)$ was also used for studies evaluating DFS. Our results showed that elevated PLR predicted a worse outcome for DFS with the combined HR of 1.404 (95\% CI: 1.169-1.687, $P<0.001$, Figure 2). Meta-analysis of these 4 studies showed that esophageal cancer patients with elevated PLR were associated with shorter CSS (HR obtained from Randomeffects model:1.686, 95\% CI: 1.146-2.480, $P<0.01$. Table $2)$ with obvious heterogeneity $\left(I^{2}=72.5 \%, P h=0.012\right)$.

\section{Sensitivity analysis}

Sensitivity analysis was performed by eliminating one study at a time and analyzing the remaining studies. The results are shown in Figure 3, the results were not substantially changed, showing the reliability and stability of our results. Furthermore, a meta-regression was also conducted to explore the potential factors that are responsible for heterogeneity in OS, The results showed that the above factors could partly explain the heterogeneity but did not reach statistical significance (Table 2).

\section{Publication bias}

The Begg's funnel plot and Egger's linear regression test were performed to analyze the publication bias. No evidence of obvious publication bias existed in DFS/CSS $(\operatorname{Pr}>|\mathrm{z}|=0.536$ for Begg's test and $P>|\mathrm{t}|=0.910$ for Egger's test). The P value of Egger's test indicated that there was publication bias in $\mathrm{OS}(P>|\mathrm{t}|=0.007)$ among these included studies. Therefore we further performed the "trim and fill" analysis. It was estimated that 1 study evaluating the prognostic value of PLR in OS remained unpublished. The filled meta-analysis concerning OS ( $\mathrm{HR}=1.361,95 \% \mathrm{CI}$ : $1.143-1.621, \mathrm{p}<0.01)$.

\section{DISCUSSION}

Our meta-analysis combined the outcomes of 6699 esophageal cancer patients from 16 studies (17 cohorts), indicating that elevated PLR significantly predicted poor OS (HR: $1.389,95 \%$ CI: 1.161-1.663, $P<0.001$, Figure 2 ) of esophageal cancer patients.

Though with heterogeneity, subgroup analyses in our study showed that elevated PLR was an effective prognostic factor for poor OS of esophageal cancer patients who had received various types of treatment including surgical resection and mixed treatment. There is also a significant association between PLR and 
dichotomized cut-off value PLR $\leq 160$ or $>160$. In addition, our pooled results demonstrated that elevated PLR was associated with poor DFS (HR: 1.404, 95\% CI: 1.169 1.687) and CSS (HR: 1.686, 95\% CI: 1.146-2.480) in patients with esophageal cancer. Taking all of these in to consideration, PLR may be as a significant biomarker in the prognosis of esophageal cancer.

Tumor associated systemic inflammatory plays an important and multifaceted role in tumor prognosis [7, 9]. The exact mechanism between inflammation and tumor was still unknown [31]. Tumor-related inflammation causes suppression of antitumor immunity by recruiting regulatory $\mathrm{T}$ cells and activating chemokines, which results in tumor growth and metastasis. The presence of both thrombocytosis and neutrophilia tends to represent a nonspecific response to cancer-related inflammation [32]. Platelets can promote tumor progression by plateletderived growth factor, platelet factor and thrombospondin $[33,34]$. It has been suggested that interleukin-4 and -5 produced from tumor-infiltrating $\mathrm{T}$ cells in tumors, might promote tumor growth and spreading $[4,35]$. Therefore, the relative value of a combined platelet and lymphocyte counts index (being expressed in the form of a PLR) can reflect the pro-tumor efficacy and antitumor capacity of the host more accurately $[34,36]$.

However, several disease conditions may affect PLR, including myocardial infarction, diabetes, renal diseases, inflammatory diseases, and infection, as well as some medications, such as antidiabetic, antibiotics drugs and cancer chemotherapy $[37,38]$. The co-occurrence of these conditions may therefore affect the prognostic ability of PLR to predict survival outcomes.

There were several limitations in this meta-analysis. Firstly, the great majority of the enrolled studies were retrospective. Thus some biases, such as information bias, misclassification bias and selection bias, may be existed in the meta-analysis. Secondly, this meta-analysis was constrained to studies published in English. Strictly, some eligible studies published in other languages might be missed. In addition, Heterogeneity is a potential problem that may affect the interpretation of the results of all metaanalyses. The presence of heterogeneity may result from many other factors, including age distribution, ethnicity, gender, PLR cut-off value and so on. Theoretically, PLR could be affected by various pathological conditions, such as infection and medications, and varies from time to time.
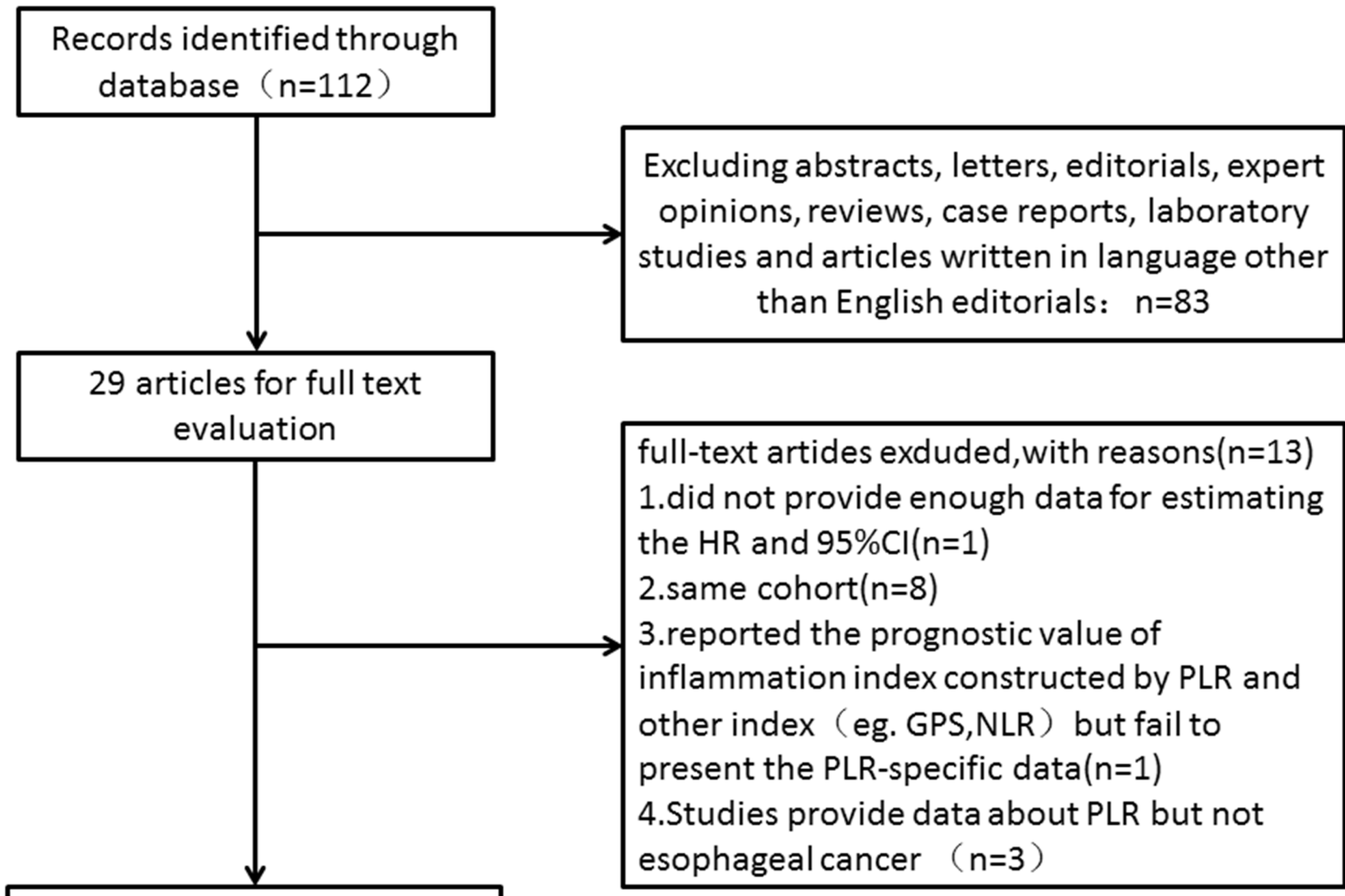

16 studies(17 cohorts) included in the meta-analysis

Figure 1: Flow chart of the included studies. 
Table 1: Main characteristics of all the studies included in the meta-analysis

\begin{tabular}{|c|c|c|c|c|c|c|c|c|c|c|c|c|}
\hline $\begin{array}{l}\text { Study } \\
\text { cohort }\end{array}$ & Year & $\begin{array}{l}\text { Study } \\
\text { region }\end{array}$ & No. (M/F) & $\begin{array}{l}\text { Follow-up (months) } \\
\text { (median and range) }\end{array}$ & Treatment & $\begin{array}{l}\text { Age (years) } \\
\text { (median and } \\
\text { range) }\end{array}$ & $\begin{array}{c}\text { cut- } \\
\text { off }\end{array}$ & Outcome & Stage & Type & HR & $\begin{array}{l}\text { NOS } \\
\text { score }\end{array}$ \\
\hline Hu D1 & 2017 & China & $1822(1822 / 0)$ & $38.2(0.5-180)$ & Surg & $55.98 \pm 9.81$ & NR & mortality & I-III & SCC & $\mathrm{R}(\mathrm{U} / \mathrm{M})$ & 6 \\
\hline $\mathrm{Hu}$ D2 & 2017 & China & $574(0 / 574)$ & $38.2(0.5-180)$ & Surg & $57.93 \pm 9.41$ & NR & mortality & I-III & $\mathrm{SCC}$ & $\mathrm{R}(\mathrm{U} / \mathrm{M})$ & 6 \\
\hline McLaren PJ & 2017 & USA & $60(48 / 12)$ & NR & $\begin{array}{l}\text { Surg/+Neo } \\
\text { CMRT }\end{array}$ & 66 & NR & OS & I-IV & $\begin{array}{l}\mathrm{ADC} / \\
\mathrm{SCC}\end{array}$ & $\mathrm{R}(\mathrm{M})$ & 4 \\
\hline Chen PC & 2016 & China & $323(281 / 42)$ & NR & Surg & $59.1 \pm 7.9$ & 150 & CSS & I-III & SCC & $\mathrm{R}(\mathrm{U} / \mathrm{M})$ & 5 \\
\hline Geng Y & 2016 & China & $916(696 / 220)$ & $39(3-146)$ & Surg & $60(37-84)$ & 120 & OS & I-III & $\mathrm{SCC}$ & $\mathrm{R}(\mathrm{U} / \mathrm{M})$ & 6 \\
\hline Hirahara N & 2016 & Japan & $147(132 / 15)$ & $42(3-111)$ & Surg & $\begin{array}{l}<70, n=46 \\
\geq 70, n=101\end{array}$ & 147 & $\mathrm{OS} / \mathrm{CSS}$ & I-IIIc & $\mathrm{SCC}$ & $\mathrm{R}(\mathrm{U})$ & 6 \\
\hline Toyokawa T & 2016 & Japan & $185(152 / 33)$ & 81.5(IQR 45.8-112.3) & $\begin{array}{c}\mathrm{Surg} / \pm \mathrm{Neo} \\
\mathrm{CMRT} / \mathrm{Neo} \\
\mathrm{CMT} / \mathrm{Neo} \\
\text { RT }\end{array}$ & $\begin{array}{l}<65, \mathrm{n}=95 \\
\geq 60, \mathrm{n}=90\end{array}$ & 193 & OS/RFS & I-IV & $\mathrm{SCC}$ & $\mathrm{R}(\mathrm{M})$ & 6 \\
\hline Zhang F & 2016 & China & $468(376 / 92)$ & $49.1 \pm 32.6(3.2-114.5)$ & Surg & $60(36-81)$ & 212 & OS/DFS & I-III & $\mathrm{SCC}$ & $\mathrm{R}(\mathrm{U} / \mathrm{M})$ & 6 \\
\hline Han LH & 2015 & China & $218(177 / 41)$ & $38.6(3-71)$ & Surg & $60.5(32-84)$ & 244 & OS/DFS & I-III & $\mathrm{SCC}$ & $\mathrm{R}(\mathrm{U} / \mathrm{M})$ & 6 \\
\hline Hyder J & 2015 & USA & $83(72 / 11)$ & 29.3 & $\begin{array}{l}\text { Surg/+Neo } \\
\text { CMRT }\end{array}$ & $59(26-82)$ & 429.7 & PFS & II-IV & $\begin{array}{l}\mathrm{ADC} / \\
\mathrm{SCC}\end{array}$ & $\mathrm{R}(\mathrm{U})$ & 6 \\
\hline Messager M & 2015 & UK & $153(128 / 25)$ & $31.8(4-131)$ & $\begin{array}{l}\text { Surg/ } \pm \text { Adj } \\
\text { CMT }\end{array}$ & $64.9(39.9-81.6)$ & 192 & OS/DFS & I-III & $\mathrm{ADC}$ & $\mathrm{R}(\mathrm{U} / \mathrm{M})$ & 6 \\
\hline $\mathrm{Xu} \mathrm{XL}$ & 2015 & China & $468(416 / 52)$ & $49.9(10.9-88.0)$ & $\begin{array}{c}\text { Surg/ } \pm \text { Adj } \\
\text { CMT/ } \pm \text { Adj } \\
\text { CMRT }\end{array}$ & 58 & 147 & OS & I-IIIc & $\mathrm{SCC}$ & $\mathrm{R}(\mathrm{U})$ & 6 \\
\hline Feng JF & 2014 & China & $483(411 / 72)$ & NR & Surg & $59.1 \pm 8.0(34-80)$ & 150 & OS & I-III & SCC & $\mathrm{R}(\mathrm{U} / \mathrm{M})$ & 5 \\
\hline Xie X & 2014 & China & $317(244 / 73)$ & $46(36-62)$ & $\begin{array}{l}\text { Surg/ } \pm \text { Adj } \\
\text { CMT }\end{array}$ & $58.1(34-76)$ & 103 & CSS & I-III & SCC & $\mathrm{R}(\mathrm{M})$ & 6 \\
\hline Yuan D & 2014 & China & $327(282 / 45)$ & $24.7(2-39)$ & $\begin{array}{c}\text { Surg } / \pm \text { Neo } \\
\text { CMT/ } / \text { Adj } \\
\text { CMT }\end{array}$ & $63.1 \pm 9.7(39-77)$ & 300 & OS/DFS & I-III & $\mathrm{SCC}$ & $\mathrm{R}(\mathrm{U})$ & 6 \\
\hline Feng JF & 2013 & China & $43(30 / 13)$ & NR & $\begin{array}{c}\text { Surg/ } \pm \text { Adj } \\
\text { CMRT }\end{array}$ & $58.7 \pm 7.8(45-74)$ & 150 & OS & I-III & $\begin{array}{c}\text { Small } \\
\text { cell }\end{array}$ & $\mathrm{R}(\mathrm{U})$ & 4 \\
\hline Dutta $S$ & 2011 & UK & $112(85 / 27)$ & 55 & $\begin{array}{c}\text { Surg/ } \pm \text { Neo } \\
\text { CMRT/ } \pm \text { Adj } \\
\text { CMRT }\end{array}$ & $\begin{array}{l}<65, \mathrm{n}=68 \\
\geq 65, \mathrm{n}=44\end{array}$ & 150 & CSS & I-IV & $\begin{array}{l}\mathrm{ADC} / \\
\mathrm{SCC}\end{array}$ & $\mathrm{R}(\mathrm{U})$ & 6 \\
\hline
\end{tabular}

ADC adenocarcinoma, Adj adjuvant therapy, CMRT chemoradiotherapy, CMT chemotherapy, CSS cancer-specific survival, DFS disease-free survival, HR hazard ratio, Neo neoadjuvant, NOS Newcastle-Ottawa Quality Assessment Scale, NR not reported, OS overall survival, PFS progression-free survival, RFS relapse-free survival, SCC squamous cell carcinoma, Surg curative surgery, R obtained by reporting in text, M means the HR come from multivariate analysis, $\mathrm{U}$ means the $\mathrm{HR}$ comes from univariate analysis.

In conclusion, our meta-analysis demonstrated that elevated PLR might be a poor prognostic factor for patients with esophageal cancer. Compared to other prognostic markers, PLR seems to be an inexpensive, widely-obtained, repeatable and reliable predictor for esophageal cancer patients. Esophageal cancer patients with high PLR may benefit from modifying inflammatory responses and modulating the immune system. In the future, more studies that are welldesigned and large-scale are needed to confirm whether PLR has a prognostic value in patients with esophageal cancer. 


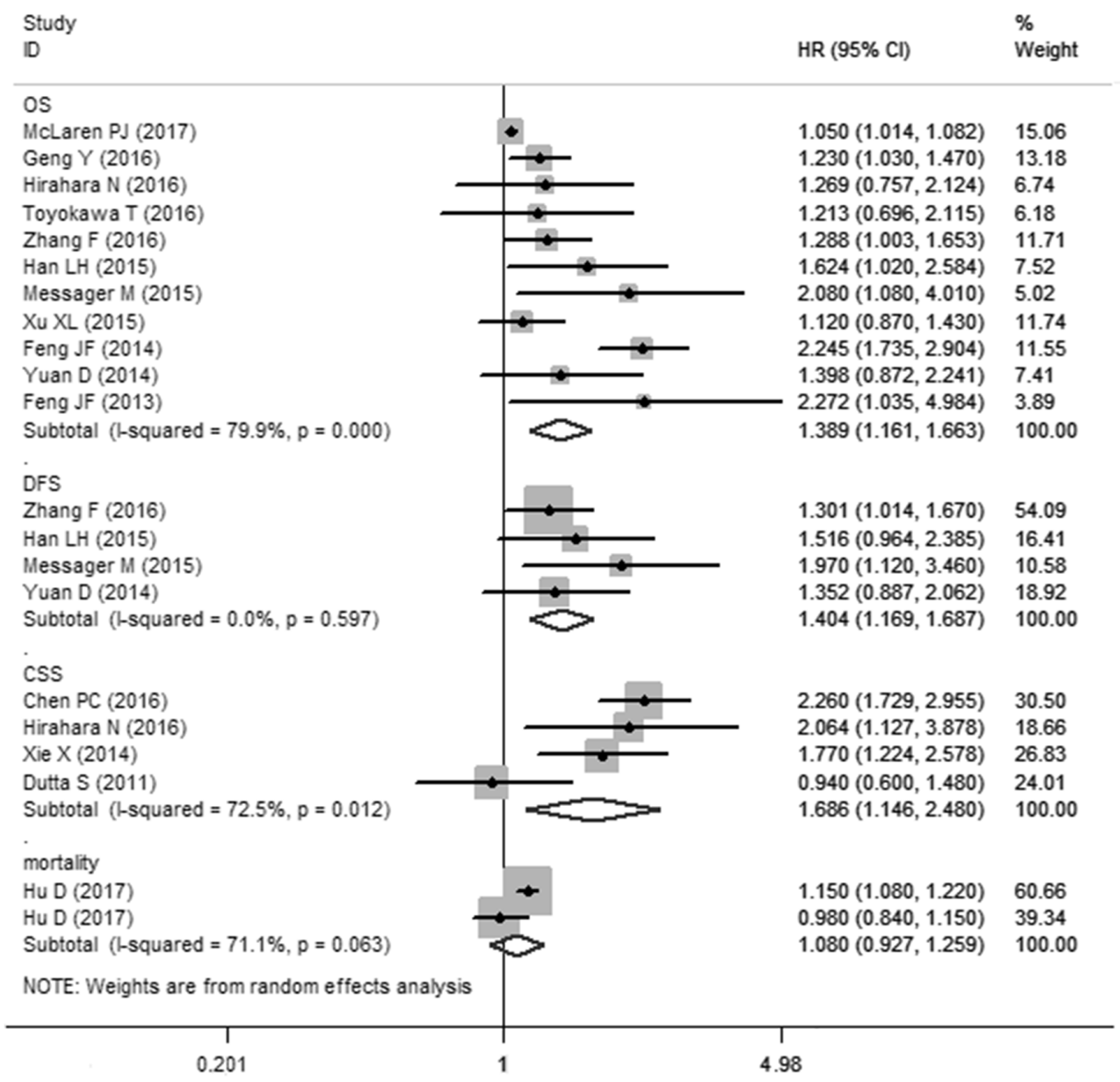

Figure 2: Meta-analysis of the association between PLR and OS/CCS/DFS/mortality of esophageal cancer.

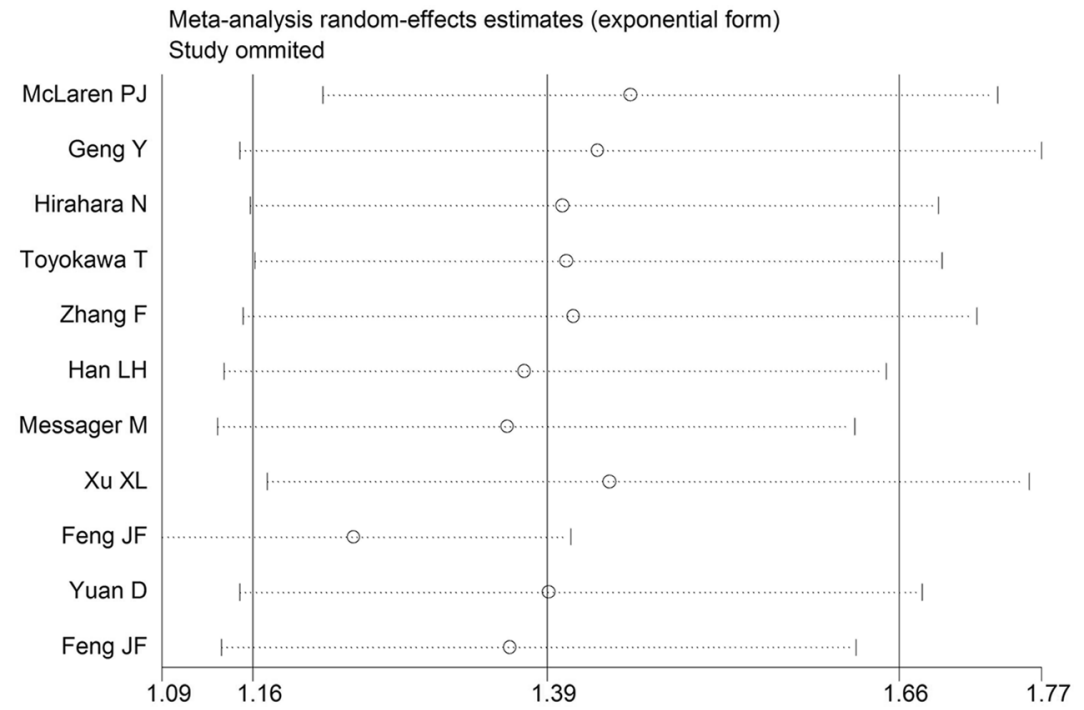

Figure 3: Sensitivity analysis for OS. 
Table 2: Summary of the meta-analysis results

\begin{tabular}{|c|c|c|c|c|c|c|c|c|c|}
\hline \multirow[t]{2}{*}{ Analysis } & \multirow[t]{2}{*}{$\mathbf{N}$} & \multicolumn{2}{|c|}{ Random-effects model } & \multicolumn{2}{|c|}{ Fixed-effects model } & \multicolumn{2}{|c|}{ Heterogeneity } & \multicolumn{2}{|c|}{ Meta-regression } \\
\hline & & HR(95\%CI) & $P$ & HR(95\%CI) & $P$ & $I^{2}$ & $P h$ & $\operatorname{adj} R^{2}$ & $P$ \\
\hline OS & 11 & $1.389(1.161,1.663)$ & 0 & $1.079(1.046,1.112)$ & 0 & $79.9 \%$ & 0 & & \\
\hline Subgroup 1: Surgery & 5 & $1.492(1.149,1.938)$ & 0.003 & $1.440(1.279,1.621)$ & 0 & $74.5 \%$ & 0.003 & $10.82 \%$ & 0.377 \\
\hline Mixed treatment & 6 & $1.222(1.009,1.479)$ & 0.04 & $1.056(1.023,1.090)$ & 0.001 & $48.4 \%$ & 0.085 & & \\
\hline $\begin{array}{l}\text { Subgroup 2: } \\
\text { Cut-off value } \leq 160\end{array}$ & 5 & $1.484(1.088,2.024)$ & 0.013 & $1.396(1.237,1.576)$ & 0 & $79.6 \%$ & 0.001 & $63.83 \%$ & 0.932 \\
\hline Cut-off value $>160$ & 5 & $1.391(1.161,1.666)$ & 0 & $1.391(1.161,1.666)$ & 0 & $0 \%$ & 0.650 & & \\
\hline $\begin{array}{l}\text { Subgroup 3: sample } \\
\text { size } \geq 300\end{array}$ & 5 & $1.404(1.096,1.799)$ & 0.007 & $1.368(1.226,1.526)$ & 0 & $78.1 \%$ & 0.001 & $70.20 \%$ & 0.908 \\
\hline sample size $<300$ & 6 & $1.376(1.047,1.809)$ & 0.022 & $1.057(1.023,1.091)$ & 0.001 & $58 \%$ & 0.036 & & \\
\hline Subgroup 4: & & & & & & & & $63.33 \%$ & 0.353 \\
\hline SCC & & $1.394(1.156,1.682)$ & 0.001 & $1.370(1.236,1.518)$ & 0 & $63.3 \%$ & 0.008 & & \\
\hline $\mathrm{ADC}$ & & $2.080(1.079,4.008)$ & - & $2.080(1.079,4.008)$ & - & - & - & & \\
\hline $\begin{array}{l}\text { Subgroup 5: } \\
\text { Univariate analysis }\end{array}$ & 9 & $1.477(1.219,1.789)$ & 0 & $1.401(1.256,1.552)$ & 0 & $63.4 \%$ & 0.005 & $68.20 \%$ & 0.215 \\
\hline Multivariate analysis & 7 & $1.225(1.026,1.462)$ & 0.024 & $1.064(1.032,1.098)$ & 0 & $73.7 \%$ & 0.002 & & \\
\hline DFS & 4 & $1.404(1.169,1.687)$ & 0 & $1.404(1.169,1.687)$ & 0 & $0 \%$ & 0.597 & & \\
\hline CSS & 4 & $1.686(1.146,2.480)$ & 0.008 & $1.814(1.505,2.186)$ & 0 & $72.5 \%$ & 0.012 & & \\
\hline mortality & 2 & $1.044(0.825,1.322)$ & 0.718 & $1.133(1.070,1.200)$ & 0 & $83.3 \%$ & 0.014 & & \\
\hline
\end{tabular}

ADC: adenocarcinoma, CI: confidence interval, CSS cancer-specific survival, DFS disease-free survival, HR hazard ratio, Mixed treatment including adjuvant/neoadjuvant \pm chemotherapy/chemoradiotherapy/radiotherapy \pm surgery, $N$ number of studies, OS overall survival, SCC squamous cell carcinoma, Ph p value of Q test for heterogeneity test.

\section{METHODS}

\section{Search strategy}

A comprehensive literature search was performed by using PubMed, Ovid, the Cochrane Library and Web of Science databases to evaluate the prognostic value of PLR in patients with esophageal cancer. Our search strategy included terms of: "PLR" (e.g., "platelet lymphocyte ratio", "platelet to lymphocyte ratio", "platelet-tolymphocyte ratio") and "esophageal neoplasm" (e.g., "esophageal cancer", "esophageal carcinoma", "esophageal squamous cell carcinoma"). The deadline of our primary search was September 30, 2017. In addition, the reference list was also scrutinized for further relevant articles.

\section{Inclusion and exclusion criteria}

Inclusion criteria for the primary analysis was as follows: (1) patients with esophageal cancers in the studies were histopathologically confirmed; (2) the PLR was measured before treatment; (3) investigated the association of PLR with overall survival (OS), disease-free survival (DFS) or cancer-specific survival (CSS); (4) full text articles in English. Exclusion criteria was as follows: (1) abstracts, letters, editorials, case reports, reviews or nonhuman research; (2) the full text was not available in English; (3) studies with insufficient data for estimating HR and $95 \% \mathrm{CI}$; (4) studies had overlapping or duplicate data.

\section{Data extraction and quality assessment}

All candidate articles were evaluated and extracted independently by two investigators (Zhao and Zhang). Any conflicts in data extraction or quality assessment were resolved by a third investigator. If the results reported had possible overlap, only the most recent or the most complete study was included in this study. We extracted data including: first author's name, year of publication, country (region), sample size, gender, follow ups, cut-off value, treatment strategy, cancer type and HRs with $95 \%$ CIs. The quality of the included studies was assessed according to the Newcastle-Ottawa Quality Assessment Scale [39], which includes three aspects of evaluation: selection (0-4 points), comparability ( $0-2$ points), and outcome assessment (0-3 points). NOS scores of $\geq 6$ were assigned as high-quality studies. 


\section{Statistical analysis}

HR and 95\%CI were obtained directly from each literature or estimation according to the methods by Parmer et al [40]. A HR $>1$ indicated a worse prognosis in esophageal cancer patients with high expression of PLR. For each meta-analysis, Cochran's Q test and Higgins I-squared statistic were undertaken to assess the heterogeneity of the included trials. $I^{2}>50 \%$ is considered as a measure of severe heterogeneity. Both fixed-effects (Mantel-Haenszel method) and random effects (DerSimonian-Laird method) models were used to calculate the pooled HRs and $95 \%$ CIs. The randomeffects model was used if there was heterogeneity between literatures; otherwise, the fixed-effects model was adopted.

Subgroup analysis was conducted to explore and explain the diversity (heterogeneity) among the results of different studies. Publication bias was assessed by Begg's funnel plot and Egger's bias test [41]. All P values were two-tailed, A $P<0.05$ was considered statistical significant. Statistical analyses were performed using STATA statistical software package version 12.0 (STATA, College Station, TX, USA).

\section{CONFLICTS OF INTEREST}

There are no conflicts of interests to declare.

\section{REFERENCES}

1. Ferlay J, Shin HR, Bray F, Forman D, Mathers C, Parkin DM. Estimates of worldwide burden of cancer in 2008: GLOBOCAN 2008. Int J Cancer. 2010; 127:2893-917. https://doi.org/10.1002/ijc.25516.

2. Li S, Liu H, Diao C, Wang X, Gao M, Li Z, Song L, Gao X, Han J, Wang F, Li W, Han X. Prognosis of surgery combined with different adjuvant therapies in esophageal cancer treatment: a network meta-analysis. Oncotarget. 2017; 8:36339-53. https://doi.org/10.18632/oncotarget.16193.

3. Markar SR, Noordman BJ, Mackenzie H, Findlay JM, Boshier PR, Ni M, Steyerberg EW, van der Gaast A, Hulshof MC, Maynard N, van Berge Henegouwen MI, Wijnhoven BP, Reynolds JV, et al. Multimodality treatment for esophageal adenocarcinoma: multi-center propensity-score matched study. Ann Oncol. 2017; 28:519-27.

4. Balkwill F, Mantovani A. Inflammation and cancer: back to Virchow? Lancet. 2001; 357:539-45. https://doi. org/10.1016/S0140-6736(00)04046-0.

5. Mantovani A, Allavena P, Sica A, Balkwill F. Cancerrelated inflammation. Nature. 2008; 454:436-44. https:// doi.org/10.1038/nature07205.

6. Mantovani A, Romero P, Palucka AK, Marincola FM. Tumour immunity: effector response to tumour and role of the microenvironment. Lancet. 2008; 371:771-83. https:// doi.org/10.1016/S0140-6736(08)60241-X.
7. Grange JM, Krone B, Mastrangelo G. Infection, inflammation and cancer. Int J Cancer. 2011; 128:2240-41. https://doi. org/10.1002/ijc.25533.

8. Song W, Wang K, Zhong FP, Fan YW, Peng L, Zou SB. Clinicopathological and prognostic significance of platelet-to-lymphocyte ratio in patients with hepatocellular carcinoma. Oncotarget. 2016; 7:81830-38. https://doi. org/10.18632/oncotarget.13244

9. Proctor MJ, Morrison DS, Talwar D, Balmer SM, Fletcher CD, O'Reilly DS, Foulis AK, Horgan PG, McMillan DC. A comparison of inflammation-based prognostic scores in patients with cancer. A Glasgow Inflammation Outcome Study. Eur J Cancer. 2011; 47:2633-41. https://doi. org/10.1016/j.ejca.2011.03.028.

10. Zhao QT, Yuan Z, Zhang H, Zhang XP, Wang HE, Wang ZK, Duan GC. Prognostic role of platelet to lymphocyte ratio in non-small cell lung cancers: A meta-analysis including 3,720 patients. Int J Cancer. 2016; 139:164-70. https://doi. org/10.1002/ijc.30060.

11. Li Y, Jia H, Yu W, Xu Y, Li X, Li Q, Cai S. Nomograms for predicting prognostic value of inflammatory biomarkers in colorectal cancer patients after radical resection. Int J Cancer. 2016; 139:220-31. https://doi.org/10.1002/ijc.30071.

12. Gu X, Gao XS, Cui M, Xie M, Peng C, Bai Y, Guo W, Han L, Gu X, Xiong W. Clinicopathological and prognostic significance of platelet to lymphocyte ratio in patients with gastric cancer. Oncotarget. 2016; 7:49878-87. https://doi. org/10.18632/oncotarget.10490.

13. Hirahara N, Matsubara T, Mizota Y, Ishibashi S, Tajima Y. Prognostic value of preoperative inflammatory response biomarkers in patients with esophageal cancer who undergo a curative thoracoscopic esophagectomy. BMC Surg. 2016; 16:66. https://doi.org/10.1186/s12893-016-0179-5.

14. Toyokawa T, Kubo N, Tamura T, Sakurai K, Amano R, Tanaka H, Muguruma K, Yashiro M, Hirakawa K, Ohira M. The pretreatment Controlling Nutritional Status (CONUT) score is an independent prognostic factor in patients with resectable thoracic esophageal squamous cell carcinoma: results from a retrospective study. BMC Cancer. 2016; 16:722. https://doi.org/10.1186/s12885-016-2696-0.

15. Zhang F, Chen Z, Wang P, Hu X, Gao Y, He J. Combination of platelet count and mean platelet volume (COP-MPV) predicts postoperative prognosis in both resectable early and advanced stage esophageal squamous cell cancer patients. Tumour Biol. 2016; 37:9323-31. https://doi.org/10.1007/ s13277-015-4774-3.

16. Han LH, Jia YB, Song QX, Wang JB, Wang NN, Cheng YF. Prognostic significance of preoperative lymphocytemonocyte ratio in patients with resectable esophageal squamous cell carcinoma. Asian Pac J Cancer Prev. 2015; 16:2245-50.https://doi.org/10.7314/APJCP.2015.16.6.2245.

17. Hirahara N, Fujii Y, Yamamoto T, Hyakudomi R, Hirayama T, Taniura T, Ishitobi K, Tajima Y. Validation of a novel prognostic scoring system using inflammatory response biomarkers in patients undergoing curative thoracoscopic 
esophagectomy for esophageal squamous cell carcinoma. Onco Targets Ther. 2017; 10:363-70. https://doi.org/10.2147/ OTT.S124556.

18. Hirahara N, Matsubara T, Kawahara D, Nakada S, Ishibashi S, Tajima Y. Prognostic significance of preoperative inflammatory response biomarkers in patients undergoing curative thoracoscopic esophagectomy for esophageal squamous cell carcinoma. Eur J Surg Oncol. 2017; 43:493501. https://doi.org/10.1016/j.ejso.2016.11.018.

19. Chen PC, Feng JF. A Novel Inflammation-Based Stage (I Stage) in Patients with Resectable Esophageal Squamous Cell Carcinoma. Mediators Inflamm. 2016; 2016:5396747. https://doi.org/10.1155/2016/5396747.

20. Geng Y, Shao Y, Zhu D, Zheng X, Zhou Q, Zhou W, Ni $\mathrm{X}, \mathrm{Wu} \mathrm{C}$, Jiang J. Systemic Immune-Inflammation Index Predicts Prognosis of Patients with Esophageal Squamous Cell Carcinoma: A Propensity Score-matched Analysis. Sci Rep. 2016; 6:39482. https://doi.org/10.1038/srep39482.

21. Hyder J, Boggs DH, Hanna A, Suntharalingam M, Chuong MD. Changes in neutrophil-to-lymphocyte and platelet-tolymphocyte ratios during chemoradiation predict for survival and pathologic complete response in trimodality esophageal cancer patients. J Gastrointest Oncol. 2016; 7:189-95.

22. Messager M, Neofytou K, Chaudry MA, Allum WH. Prognostic impact of preoperative platelets to lymphocytes ratio (PLR) on survival for oesophageal and junctional carcinoma treated with neoadjuvant chemotherapy: A retrospective monocentric study on 153 patients. Eur J Surg Oncol. 2015; 41:1316-23. https://doi.org/10.1016/j. ejso.2015.06.007.

23. Xu XL, Yu HQ, Hu W, Song Q, Mao WM. A Novel Inflammation-Based Prognostic Score, the C-Reactive Protein/Albumin Ratio Predicts the Prognosis of Patients with Operable Esophageal Squamous Cell Carcinoma. PLoS One. 2015; 10:e0138657. https://doi.org/10.1371/journal. pone. 0138657 .

24. Feng JF, Huang Y, Chen QX. Preoperative platelet lymphocyte ratio (PLR) is superior to neutrophil lymphocyte ratio (NLR) as a predictive factor in patients with esophageal squamous cell carcinoma. World J Surg Oncol. 2014; 12:58. https://doi.org/10.1186/1477-7819-12-58.

25. Xie X, Luo KJ, Hu Y, Wang JY, Chen J. Prognostic value of preoperative platelet-lymphocyte and neutrophil-lymphocyte ratio in patients undergoing surgery for esophageal squamous cell cancer. Dis Esophagus. 2016; 29:79-85. https://doi. org/10.1111/dote.12296.

26. Yuan D, Zhu K, Li K, Yan R, Jia Y, Dang C. The preoperative neutrophil-lymphocyte ratio predicts recurrence and survival among patients undergoing R0 resections of adenocarcinomas of the esophagogastric junction. J Surg Oncol. 2014; 110:333-40. https://doi.org/10.1002/jso.23651.

27. Feng JF, Huang Y, Zhao Q, Chen QX. Clinical significance of preoperative neutrophil lymphocyte ratio versus platelet lymphocyte ratio in patients with small cell carcinoma of the esophagus. Sci World J. 2013; 2013:504365. https://doi. org/10.1155/2013/504365.

28. Dutta S, Crumley AB, Fullarton GM, Horgan PG, McMillan DC. Comparison of the prognostic value of tumour- and patient-related factors in patients undergoing potentially curative resection of oesophageal cancer. World J Surg. 2011; 35:1861-66. https://doi.org/10.1007/s00268-011-1130-7.

29. McLaren PJ, Bronson NW, Hart KD, Vaccaro GM, Gatter KM, Thomas CR Jr, Hunter JG, Dolan JP. Neutrophil-toLymphocyte and Platelet-to-Lymphocyte Ratios can Predict Treatment Response to Neoadjuvant Therapy in Esophageal Cancer. J Gastrointest Surg. 2017; 21:607-13. https://doi. org/10.1007/s11605-016-3351-4.

30. Hu D, Lin X, Chen Y, Chang Q, Chen G, Li C, Zhang H, Cui Z, Liang B, Jiang W, Ji K, Huang J, Peng F, et al. Preoperative blood-routine markers and prognosis of esophageal squamous cell carcinoma: the Fujian prospective investigation of cancer (FIESTA) study. Oncotarget. 2017; 8:23841-50. https://doi.org/10.18632/oncotarget.13318.

31. Moore MM, Chua W, Charles KA, Clarke SJ. Inflammation and cancer: causes and consequences. Clin Pharmacol Ther. 2010; 87:504-08. https://doi.org/10.1038/clpt.2009.254.

32. Cheng J, Zeng Z, Ye Q, Zhang Y, Yan R, Liang C, Wang J, $\mathrm{Li}$ M, Yi M. The association of pretreatment thrombocytosis with prognosis and clinicopathological significance in cervical cancer: a systematic review and meta-analysis. Oncotarget. 2017; 8:24327-36. https://doi.org/10.18632/ oncotarget.15358.

33. Gay LJ, Felding-Habermann B. Contribution of platelets to tumour metastasis. Nat Rev Cancer. 2011; 11:123-34. https://doi.org/10.1038/nrc3004.

34. Bambace NM, Holmes CE. The platelet contribution to cancer progression. J Thromb Haemost. 2011; 9:237-49. https://doi.org/10.1111/j.1538-7836.2010.04131.x.

35. Germano G, Allavena P, Mantovani A. Cytokines as a key component of cancer-related inflammation. Cytokine. 2008; 43:374-79. https://doi.org/10.1016/j.cyto.2008.07.014.

36. Kim SH, Lee HW, Go SI, Lee SI, Lee GW. Clinical significance of the preoperative platelet count and plateletto-lymphocyte ratio (PLT-PLR) in patients with surgically resected non-small cell lung cancer. Oncotarget. 2016; 7:36198-206. https://doi.org/10.18632/oncotarget.8809.

37. Trakarnwijitr I, Li B, Adams H, Layland J, Garlick J, Wilson A. Age modulates the relationship between plateletto-lymphocyte ratio and coronary artery disease. Int $\mathrm{J}$ Cardiol. 2017; 248:349-54. https://doi.org/10.1016/j. ijcard.2017.06.127.

38. Hudzik B, Szkodziński J, Lekston A, Gierlotka M, Poloński L, Gąsior M. Mean platelet volume-to-lymphocyte ratio: a novel marker of poor short- and long-term prognosis in patients with diabetes mellitus and acute myocardial infarction. J Diabetes Complications. 2016; 30:1097-102. https://doi.org/10.1016/j.jdiacomp.2016.04.010. 
39. Wells GA, Shea B, O'Connell D, Peterson J, Welch V, Losos M, Tugwell P. The Newcastle-Ottawa Scale (NOS) for assessing the quality of nonrandomised studies in metaanalyses. Available at: www.ohri.ca/programs/clinical_ epide-miology/oxford.asp.

40. Parmar MK, Torri V, Stewart L. Extracting summary statistics to perform meta-analyses of the published literature for survival endpoints. Stat Med. 1998; 17:2815-34.
41. Egger M, Davey Smith G, Schneider M, Minder C. Bias in meta-analysis detected by a simple, graphical test. BMJ. 1997; 315:629-34. https://doi.org/10.1136/bmj.315.7109.629. 